5. Храмченкова А.О. Актуализация методики нормирования механизированных полевых работ, выполняемых современной импортной техникой // Агропродовольственная политика России. - 2016.№ $10-(58)$. - С. 23-25.

6. Храмченкова А.О. Стимулирование труда работников сельскохозяйственных предприятий в условиях рынка: дис. ... канд. экон. наук; Российский государственный аграрный университет Московская сельскохозяйственная академия им. К.А. Тимирязева. - М., 2000. -Режим доступа: https:// elibrary.ru/author items.asp.

Бутырин Василий Владимирович, д-р экон. наук, проф. кафедры «Организация производства и управления бизнесом в АПК», Саратовский государственный аграрный университет имени Н.И. Вавилова. Россия.
Бутырина Юлия Александровна, канд. экон. наук, доцент кафедры «Организация производства и управления бизнесом в АПК», Саратовский государственный аграрный университет имени Н.И. Вавилова. Россия.

Моренова Елена Александровна, канд. экон. наук, доцент кафедры «Менеджмент в АПК», Саратовский государственный аграрный университет имени Н.И. Вавилова. Россия.

Черненко Елена Владимировна, канд. экон. наук, доиент кафедры «Менеджмент в АПК», Саратовский государственный аграрный университет имени Н.И. Вавилова. Россия.

10012, г. Саратов, Театральная пл., 1.

Тел.: (8452) 26-27-83., e-mail: el.chernenko@yandex.ru

Ключевъе слова: агробизнес; растениеводство; колебания иен; эффективность; рентабельность.

\title{
PRICE FLUCTUATIONS INFLUENCE ON AGRIBUSINESS DEVELOPMENT
}

Butyrin Vasily Vladimirovich, Doctor of Economic Sciences, Professor of the chair "Production Organization and Business Management in Agriculture”, Saratov State Agrarian University named after N.I. Vavilov. Russia.

Butyrina Yulia Alexandrovna, Candidate of Economic Sciences, Associate Professor of the chair "Production Organization and Business Management in Agriculture”, Saratov State Agrarian University named after N.I. Vavilov. Russia.

Morenova Elena Aleksandrovna, Candidate of Economic Sciences, Senior Teacher of the chair "Management in Agrarian and Industrial Complex”, Saratov State Agrarian University named after N.I. Vavilov. Russia.

Chernenko Elena Vladimirovna, Candidate of Eco- nomic Sciences, Senior Teacher of the chair "Management in Agrarian and Industrial Complex”, Saratov State Agrarian University named after N.I. Vavilov. Russia.

Keywords: agribusiness; crop production; price fluctuations; efficiency; profitability.

The influence of various factors on the efficiency of agricultural production on the example of crop production is considered. On the basis of calculations it is proved that the most powerful impact on the efficiency and development of agribusiness is provided by price fluctuations in agricultural markets.

Удк 338.433(045)

\section{АНАЛИЗ ПРОБЛЕМ РАЗВИТИЯ ОТЕЧЕСТВЕННОГО АПК И ОСОБЕННОСТЕЙ ПРОВЕДЕНИЯ ПРОЦЕДУР БАНКРОТСТВА}

\author{
ДАНИЛОВА Наталия Федоровна, Саратовский социально-экономический институт (филиал) \\ РЭУ им. Г.В. ПлеХанова
}

КАБАНЦЕВА Наталия Гавриловна, Саратовский национальный исследовательский государственный университет имени Н.Г. Чернышевского.

САРАЕВА Ирина Викторовна, Саратовский социально-экономический институт (филиал)

РЭУ им. Г.В. Плеханова

Рассматриваются проблемы развития отечественного АПК, в том числе проблемы несостоятельности сельхозтоваропроизводителей. Выделены факторы, обусловливающие низкие темпы развития отечественного агропромышленного комплекса. Дан анализ процедуры банкротства, сделаны выводы по проблемам развития отечественного АПК и особенностям проведения процедур банкротства в отнощении сельхозтоваропроизводителей.

Введение. Исследования, проводимые отечественными и зарубежными специалистами, показали, что АПК является важнейшим звеном мировогохозяйства в целом и отдельных стран в частности, в нем производится жизненно важная для граждан продукцияи сосредоточен огромный экономических потенциал. Предметом исследования является методический аппарат оценки риска банкротства российскихсельскохозяйственных предприятий (организаций).
Методика исследований. Исследование основано на диалектической теории научного познания, единстве логического анализа и исторического развития. В работе использованы системный подход, дедукция и индукция, методы экономического и статистического анализа, современные методы построения экономических моделей.

Резулътаты исследований. Изучение широкого спектра отечественных и зарубежных публикаций и материалов, посвященных исследованию 
мирового продовольственного рынка, продовольственной безопасности государств позволяют, по мнению авторов, провести своеобразную группировку стран по степени обеспеченности их граждан продовольствием, а именно: высокообеспеченные, среднеобеспеченные, малообеспеченные. К первой группе следует отнести США, Канаду, Японию, страны Западной Европы и ряд других, то есть государства, имеющие в достаточном объеме и качестве основные виды продовольствия. Вторая группа стран характеризуется наличием нормального рациона питания. К таким странам относятся достаточно развитые страны, такие как Россия, Китай, практически все восточноевропейские страны, входившие ранее в социалистический лагерь, а также ряд государств Африки и Южной Америки. Большинство африканских и азиатских стран составляют третью группу, для которой характернынищета, голод, деградация населения.

При этом следует отметить, что продовольственная проблема в мире объясняется низкой эффективностью сельского хозяйства во многих странах. Это можно проиллюстрировать статистическими данными, в частности страны первой группы, обладающие $1 / 4$ сельскохозяйственных земель, где проживает около 1/4 населения планеты, создают 60 \% мирового продовольственного фонда. В то же время страны, входящие в третью группу, располагая значительно большими земельными и трудовыми ресурсами, производят лишь около 20 \% продовольствия [1, 4].

Крупнейшим мировым экспортером продовольствия по праву считается Европа, о чем свидетельствует её доля в мировом продовольственном экспорте за 2015 г. (рис. 1) [3].

Внешнеторговое сальдо России в разрезе продукции АПК продолжает оставаться отрицательным. Так, в 2014 г. оно составило 20,8 млн долл., что несколько меньше чем в предыдущие годы, например, в послекризисный 2010 г. оно составило 27,6 млрд долл., в 2011 г. соответственно 29,2 млрд долл.

Динамика российского экспорта и импорта продовольственных товаров и сельскохозяйственного сырья представлена на рис. 2 [3].

Как видно из представленных данных, в последние годы в сельском хозяйстве России наблюдался некоторый рост. Об этом свидетельствует показатель добавленной стоимости, создаваемой в сельском хозяйстве, которая увеличилась за ана-

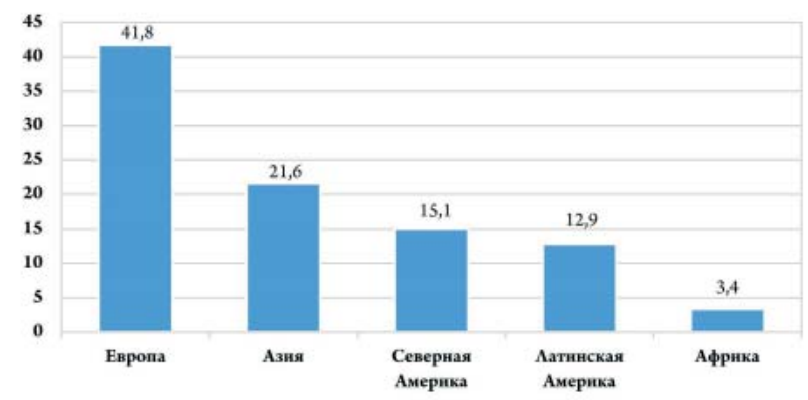

Рис. 1. Экспорт продовольствия в мире за 2015 г., \%

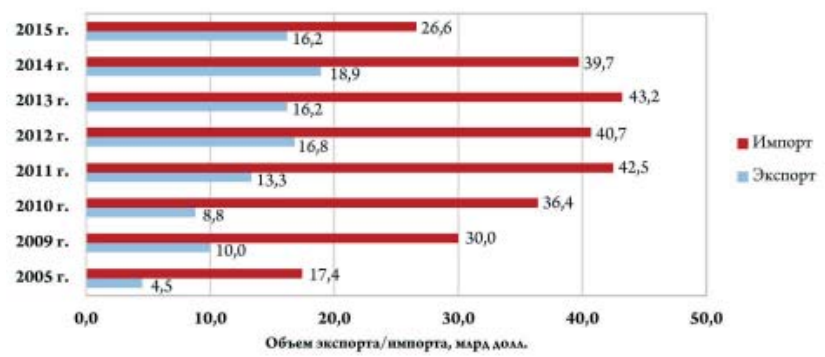

Рис. 2. Динамика экспорта и импорта продовольственных товаров и сельскохозяйственного сыръя в РФ, млрд долл. (в фактически действовавиих ценах)

лизируемый период в 3,3 раза. Однако переломить ситуацию с вытеснением отечественного продовольствия иностранным не удается. Не помогли решить положительно данный вопрос и санкции со стороны России в виде эмбарго.

Основными факторами, обусловливающиминизкие темпы развития отечественного агропромышленного комплекса, следует, на наш взгляд, считать:

отсутствие макроэкономической стабильности в стране;

внутриотраслевые проблемы АПК в виде низких темпов внедрения достижений научно-технического прогресса, речь идет о структурных и технологических преобразованиях;

недостаточное развитие инфраструктуры отрасли, что сказывается на снижении эффективности ее функционирования, слабой связи с продовольственным рынком страны;

проблема снижение инвестиций в отрасль; а также недостаточный уровень развития страховых услугв сельском хозяйстве;

влияние антироссийских санкций на развитие рынков сельхозпроизводителей;

отсутствие в достаточной мере квалифицированных кадров, обусловленное низким качеством и уровнем жизни на селе;

низкий уровень эффективности государственной поддержки сельхозпроизводителей, отсутствие эффективного института несостоятельности (банкротства) сельхозпредприятий.

Проведенные исследования позволяют утверждать, что внутренний рынок перенасыщен импортными продовольственными товарами. В частности, при пороговом значении в 20 \%, обеспечивающим по международным стандартам продовольственную безопасность государства, в стране он достигает $70 \%$.

Данные обстоятельства приводят к необходимости государственного регулирования аграрного сектора экономики, необходимость продолжения политики его субсидирования с целью повышения эффективности его функционирования и решения проблемы продовольственной безопасности страны.

В свете этого Правительством РФ ставятся вопросы о регулировании цен на сельскохозяйственную продукцию, повышение эффективности контроля на рынке продовольственных товаров, 
- решение проблем с увеличением инвестиций и развитием инфраструктуры отрасли [3].

Наряду с представленными выше направлениями государственного регулирования и поддержки деятельности отечественного АПК, важное значение имеет, на наш взгляд, и комплекс мер, связанных непосредственно со стабилизацией финансового состояния сельхозпроизводителей, одним из элементов которого является механизм несостоятельности (банкротства).

Острота проблемы несостоятельности сельхозтоваропроизводителей обусловлена воздействием такого значимого фактора, как воздействие макроэкономической нестабильности в стране [5, c. 86]. Данный фактор обусловил хроническую неплатежеспособность отрасли и ставит под угрозу дальнейшую перспективу ее развития, существование потенциальной угрозы банкротства. Динамика банкротств в аграрном секторе экономики представлена на рис. 3.

Решение проблемы обеспечения экономической и продовольственной безопасности нашего государства напрямую зависит от ускорения экономических преобразований в сельском хозяйстве, от повышения эффективности проведения процедур банкротства сельхозпредприятий, механизмов их финансового оздоровления. Это требует анализа возможности развития аграрного сектора за счет привлечения в отрасль эффективных собственников. Для этого необходимо разрабатывать законодательные основы, защищающие их права и интересы.

Действенным способом повышения эффективности аграрного сектора является процедура санации, банкротства сельскохозяйственных предприятий. Как известно, банкротство способствует оздоровлению экономики только в циклических кризисах. Банкротство - специфический саморегулятор любого рынка. Проведение соответствующих мероприятий повышает эффективность экономики страны. Однако Россия сейчас находится в другом периоде, связанном с переходными процессами, в котором механизм самокоррекции как экономики в целом, так и АПК в частности отсутствует. Вследствие этого, на наш взгляд, одним из направлений преодоления кризисных явлений в АПК должно стать не тотальное банкротство, ликвидация отечес-

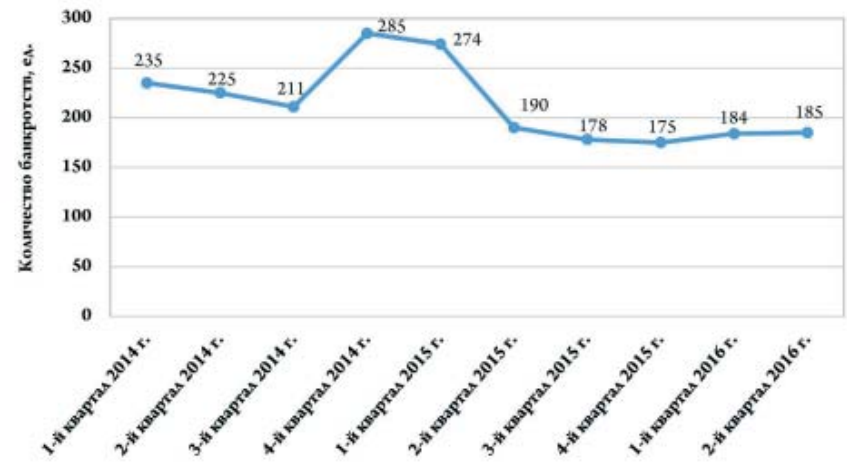

Рис. 3. Динамика банкротств сельскохозяйственных предприятий [5] твенных сельхозпредприятий, а определенный спектр мероприятий, предпринимаемых для предотвращения банкротства. Некоторые позитивные сдвиги в этом направлении наблюдаются в последнее время, о чем свидетельствуют данные представленные на рис. 4.

В частности статистика позволяет констатировать некоторое снижение количества банкротств в АПК к концу 2015 г. и устойчивое снижение доли банкротств в аграрном секторе экономики на протяжении 2014-2015 гг. Позитивное влияние на столь удачное для сельхозтоваропроизводителей изменение отраслевой структуры банкротств оказало как не странно введение западных санкций. Благодаря положительному эффекту «контрсанкций» импортозамещение продолжает оказывать своеобразную поддержку отечественному аграрию. В частности, отмечается стойкая тенденция роста объема производства продукции сельского хозяйства в 2015 г. и начале 2016 г., что, в свою очередь, способствовало увеличению прибыли и снижению объемов кредиторской задолженности в АПК.

Как показывают исследования, специфика аграрного сектора экономики проявляется помимо производственной, организационно-правовой сферы также и в осуществлении финансовой деятельности, в том числе в применении законодательства о несостоятельности (банкротстве). Учет особенностей финансовой деятельности сельхозтоваропроизводителей, применения к ним процедур банкротства регламентирован §3 гл. IX Федерального закона «О несостоятельности (банкротстве)» [6].

Процедуры банкротства, предусмотренные указанным выше параграфом, могут быть применены в отношении должника только при наличии у него в совокупности всех характеристик сельскохозяйственной организации, предусмотренных законом, а именно: статуса юридического лица; цели создания и деятельности, предусматривающих изготовление, выпуск и переработку товаров сельскохозяйственной направленности; размера выручки, полученной в результате реализации (изготовления/переработки) и последующей реализации) сельскохозяйственных товаров (продукции), которая должна составлять не менее половины (50 \%) общей суммы вырученных средств.

Нормы §3 гл. IX закона распространяются и на рыболовецкие артели (колхозы) при наличии дан-

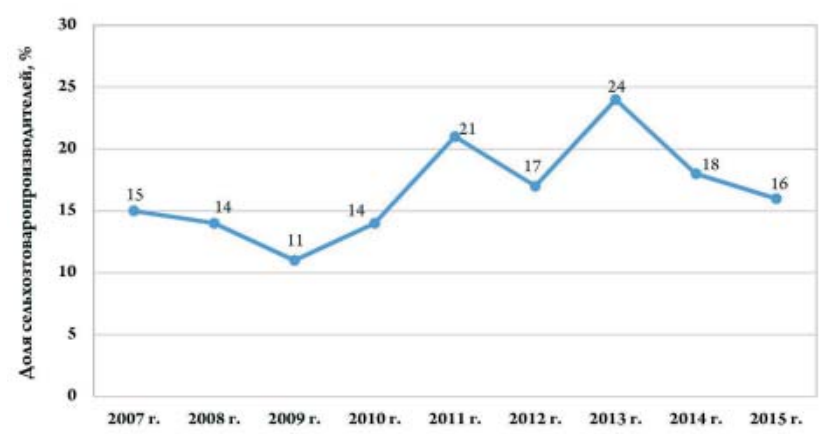

Рис. 4. Динамика удельного веса банкротов-сельхозтоваропроизводителей в общем количестве банкротств юридических лии, \% [5] 
ных о том, что размер получаемых в результате их деятельности средств (за продажу изготовленных/ переработанных) сельскохозяйственных товаров и уловов) равен или превышает 70 \% их общей прибыли.

Из этого следует, что сельскохозяйственными организациями считаются как сами производитель сельскохозяйственной продукции, так и предприятия по ее переработке. Сельскохозяйственные организации имеют свою специфику в зависимости от организационно-правовых форм, отраслевой принадлежности, на которую влияют какие факторы, как сезонность (цикличность), длительность периода проведения работ; повышенный риск деятельности, высокий уровень зависимости от внешних, в том числе природных рисков; а также особенность структуры имущественного комплекса, проявляющейся в значительной доле: неликвидного имущества; имущества, требующего постоянного ухода и затрат, объектов социальной сферы, инженерной инфраструктуры, обслуживающих не только это хозяйство.

Перечисленные выше особенности нашли отражение в отечественном законодательстве о банкротстве путем формирования особого подхода к осуществлению традиционных для юридических лиц процедур банкротства относительно сельхозтоваропроизводителей. Их характеристика отражена в ст. 178, в которой прописаны процедуры банкротства в данной отрасли, в зависимости от таких моментов, как наблюдение, финансовое оздоровление, внешнее управление, а также конкурсная реализация имущества и имущественных прав (ст. 179) [6].

Так, при наблюдении предполагается анализ состояния предприятия с точки зрения наличия и использования финансовых ресурсов, учитывается сезонность, природно-климатические условия и возможность расчета с кредиторами по завершении сельскохозяйственных работ.

Законом предусмотрены такие процедуры, как финансовое оздоровление предприятия и введение внешнего управления. Основным моментом их проведения является учет фактора времени, а именно до окончания периода сельхозработ, при этом дается время на реализацию ипереработку произведенной продукции. Ст. 178 предусматривает также возможность чрезвычайных обстоятельств, при которой необходимо провести изменение графика погашения задолженности и продлить сам срок финансового оздоровления на один год. А также возможно продление внешнего управления на год.

Ст. 179 предусматривает процедуру конкурсной реализации имущества и имущественных прав. На осуществление данной процедуры могут претендовать только те лица, которые занимаются данным производством или работают в области переработки сельскохозяйственной продукции. Обязательным условием является наличие земельного участка вблизи участка должника. Эта процедура применима и к крестьянскому (фермерскому) хозяйству.
Заключение. Подводя итоги проведенного сеисследования проблем развития отечественного АПК и особенностей проведения процедур банкротства в отношении сельхозтоваропроизводителей можно констатировать следующее:

1. Несмотря на предпринимаемые государством меры, внешнеторговое сальдо России в разрезе продукции АПК продолжает оставаться отрицательным, что негативным образом сказывается на продовольственной безопасности страны. Внутренний рынок перенасыщен импортными продовольственными товарами, что существенно превышает пороговое (нормативное) значение (20 \%). Основными факторами, обусловливающими данное явление, являются диспропорции и отсутствие макроэкономической стабильности в экономике России, низкие темпы структурных и технологических преобразованиях; недостаточное развитие инфраструктуры отрасли, проблема снижение инвестиций в отрасль, влияние антироссийских санкций на развитие рынков сельхозпроизводителей, отсутствие в достаточной мере квалифицированных кадров, обусловленное низким качеством и уровнем жизни на селе, недостаточная государственная поддержка сельхозтоваропроизводителей, отсутствие эффективного института несостоятельности (банкротства) сельхозпредприятий;

2. Отмечается некоторое снижение количества банкротств в АПК к концу 2015 г. и устойчивое снижение доли банкротств в аграрном секторе экономики на протяжении 2014-2015 гг., что вызвано, на наш взгляд, положительным эффектом «контрсанкций», предпринимаемых государством, и развитием импортозамещения. В частности, отмечается устойчивая тенденция роста объема производства продукции сельского хозяйства в 2015 г. и начале 2016 г., что, в свою очередь, способствовало увеличению прибыли иснижению объемов кредиторской задолженности в АПК;

3. Правительством РФ был принят закон «О несостоятельности (банкротстве)», который определил особенность проведения соответствующих процедур. Это отразилось в формулировании количественного критерия в процентах от реализации продукции; в увязке вопросов отчуждения или перехода земельных участков от должника к другому лицу в соответствии с земельным законодательством; в учете сезонности сельскохозяйственного производства и возможности возникновения чрезвычайных обстоятельств для проведения таких процедур, как наблюдение, финансовое оздоровление, введение внешнего управления, а также продления срока проведения ряда процедур.

Однако следует отметить,что некоторые аспекты деятельности сельхозтоваропроизводителей в законодательстве учтены недостаточно. В частности, не выражены экономические признаки определения несостоятельности сельскохозяйственной организации, отсутствуют рыночные механизмы оценки объектов недвижимости и других активов сельскохозяйственных предприятий, оценки бизнеса в процессе проведения процедур банкротства. 
Необходимо также отметить дефицит квалифицированных кадров, способных осуществлять антикризисное управление именно АПК с учетом его специфики, а также отсутствие системы комплексных государственных мер по оказанию поддержки организациям-должникам.

\section{СПИСОК ЛИТЕРАТУРЫ}

1. Вотиева 3.А. Роль сельского хозяйства в обеспечении продовольственной безопасности России // Известия УрГЭУ. - 2011. - №5(37).- С. 177-182.

2. Данилова Н.Ф., Коновалова Т.Л., Сараева И.В. Некоторые проблемы аграрного сектора России в условиях международных санкций // Аграрный научный журнал. - 2017. - № 11. - С. 86-90.

3. Минтусов В.К. Направления совершенствования регулирования импорта продовольствия в Российской федерации: дис. ... канд. экон. наук. -М., 2016. - 157 c.

4. Минченко Л.В., Соколова Е.А. Продовольственная безопасность России, роль сельского хозяйства в ее обеспечении // Научный журнал НИУ ИТМО. Серия «Экономика и экологический менеджмент.2014. - № 4.- С. 284-301.

5. Официальный сайт Федеральной службы гос- статистики. - Режим доступа: gks.ru.

6. О несостоятельности (банкротстве): [Федер. закон: принят Гос. Думой 26 окт. 2002 г.: по состоянию на 3 июля 2016]. - Режим доступа: http://www. consultant.ru.

Данилова Наталия Федоровна, канд. экон. наук, доиент кафедры «Экономическая теория», Саратовский социально-экономический институт (филиал) РЭУ им. Г.В. Плеханова. Россия.

410003, г. Саратов, ул. Радищева, 89.

Тел.:(8452)36-28-23.

Кабанцева Наталия Гавриловна, канд. экон. наук, доцент кафедры «Финансы и кредит», Саратовский национальный исследовательский государственный университет имени Н.Г. Чернышевского. Россия.

410013, г. Саратов, ул. Астраханская , 83.

Тел.: (8452) 21-36-44.

Сараева Ирина Викторовна, канд. сочиол. наук, доиент кафедры «Финансы», Саратовский социально-экономический институт (филиал) РЭУ им. Г.В. Плеханова. Россия.

410003, г. Саратов, ул. Радищева, 89.

Тел.:(8452)36-28-23.

Ключевые слова: сельскохозяйственные предприятия; не состоятельность; банкротство; наблюдение; финансовое оздоровление; конкурсная реализация имущества и имущественных прав.

\title{
ANALYSIS OF PROBLEMS OF DEVELOPMENT OF DOMESTIC AGRICULTURE AND IMPLEMENTATION OF BANKRUPTCY PROCEDURES
}

Danilova Natalia Fedorovna, Candidate of Economic Sciences, Associate Professor of the chair "Economic Theory", Saratov Socio-economic Institute (branch) of Russian Economic University named after G.V. Plekhanov. Russia.

Kabantseva Natalia Gavrilovna, Candidate of Economic Sciences, Associate Professor of the chair "Finance and Credit”, Saratov State National Research University named after N.G. Chernyshevskiy. Russia.

Saraeva Irina Viktorovna, Candidate of Sociological Sciences, Associate Professor of the chair "Finance", Saratov Social and Economic University (branch), Russian Economic University named after G.V. Plekhanov. Russia.
Keywords: agricultural enterprises; insolvency; bankruptcy; supervision; financial rehabilitation; competitive sale of property and property rights.

In the article the problems of national agro-industrial complex development are examined, including the problem of the farmers' insolvency. The factors which are responsible for the slow pace of domestic agriculture's development are highlighted. The analysis of the bankruptcy procedure, the conclusions on the development of domestic agriculture and the peculiarities of bankruptcy proceedings against the farmers are included.

УдК 368.025.61. 332.14

\section{МЕТОДИЧЕСКИЕ ПОДХОДЫ И ОПЫТ КОЛИЧЕСТВЕННОЙ ОЦЕНКИ ФИНАНСОВЫХ РИСКОВ СЕЛЬСКОХОЗЯЙСТВЕННЫХ ПРЕДПРИЯТИЙ}

\author{
МЕЛЬНИКОВА Юлия Владимировна, Саратовский государственный аграрный университет \\ имени Н.И. Вавилова
}

ОСИПОВА Наталья Николаевна, Саратовский государственный аграрный университет имени Н.И. Вавилова

Представлены результаты анализа риска ликвидности для сельскохозяйственнъх предприятий - производителей растениеводческой продукции Новоузенского района Саратовской области. Установлена прогнозная оценка уровня финансового риска в зависимости от объемов производства и рыночных иен. Авторами выделены наиболее действенные меры по управлению финансовыми рисками для аграрного сектора экономики.

Введение. В условиях рыночных отношений проблема анализа и оценки рисков приобретает всё большее значение. Потребность в исследованиях в данной области является актуальной, поскольку проблема риска тесно связана с финансовой устойчивостью организации, позво- ляющей ей свободно маневрировать денежными средствами, обеспечивать своевременность платежей и расширение производства. Особое значение вопрос измерения рисков приобретает в агропромышленном комплексе, поскольку функционирование сельскохозяйственных пред- 